\title{
Objectification of Diagnostic Symptoms in Examination of Nervous System Damage by Static Interactions and Kinematic Parameters of Ankle Joint
}

\author{
Sz. Nitkiewicz ${ }^{a, *}$, M. Śmieja $^{a}$, T. Gogolewski ${ }^{a}$, A. MajChrowski ${ }^{b}$, E. GrabarczyK $^{b, c}$ \\ AND W. MAKSYMOWICZ ${ }^{b, c}$ \\ ${ }^{a}$ Department of Mechatronics and IT Education, Faculty of Technical Sciences \\ University of Warmia and Mazury in Olsztyn, Słoneczna 46a, 10-710 Olsztyn, Poland \\ ${ }^{b}$ Hospital of University of Warmia and Mazury in Olsztyn \\ Neurosurgery Clinic, Warszawska 30, 10-082 Olsztyn, Poland \\ ${ }^{c}$ Department of Neurology and Neurosurgery, Faculty of Medical Sciences \\ University of Warmia and Mazury in Olsztyn, Warszawska 30, 10-082 Olsztyn, Poland
}

\begin{abstract}
Current diagnostics of patients' condition as well as assumed effects of the used medical diagnostic methods are a significant part of every medical treatment. The process of continuous gathering experience and comparing it with current knowledge leads to development of medical sciences and still growing effectiveness in practice. Numerous relations between particular human body systems and their interactions are very important for fast and precise diagnosis. In the paper, evaluation of the effects of neurosurgical procedures expressed as improvement of mechanical parameters of skeleton muscle system have been considered. The approach presented in the paper assumes description of results in terms of common physical units.
\end{abstract}

DOI: 10.12693 /APhysPolA.125.A-27

PACS: 87.85.G-, 87.85.Ox, 87.85.Tu

\section{Introduction}

The goal of surgery interference in a human body is improvement of its life functions. Ability to move or to sense as indirect features of a human body is a condition for evaluating the state of neural system. The explicit example of relations between neuro disorders and motion ability is the set of symptoms connected with lumbar discopathy which is one of the most common causes of the lower limb paresis. Paresis is a condition typified by a weakness of voluntary movement, partial loss of voluntary movement, or impaired movement.

In the article we consider the lumbar discopathy disorder. If a nerve root is pressed by a herniated intervertebral disc, dysfunction of the compresses root occurs and consequential restriction to the communication between the central nervous system and muscle motor units $[1,2]$.

Lower limb paresis caused by discopathy is a condition that requires prompt diagnosis and urgent surgical intervention. Failure to undertake immediate treatment can lead to permanent damage of the compressed nerve root and to perpetuate the paralysis which results in permanent movement disability.

The treatment is based on mechanical removal of a portion of the intervertebral disc or other degenerated spinal

*corresponding author; e-mail: szymon.nitkiewicz@uwm.edu.pl components in order to achieve decompression of the nerve root while maintaining the stability of the spine. Results of the postoperative neurological examinations demonstrate a correlation between improved nerve function and motion abilities in the lower limb. Postoperative neurological improvement and a good surgical outcome must be interpreted as an effect of successful root decompression [3].

Taking into account motion abilities, several different methods to express these features as symptoms of neurological disorder are commonly used. These are methods to state mechanical interaction in the area of ankle joints. Due to their specificity, they are used to estimate values associated with various medical aspects. The methods including the Manual Muscle Testing (MMT), for example the Maximum Voluntary Contraction (MVC), the Medical Research Council Scale (MRC), or the Lovett Scale, are presented in Tables I-III.

\section{Overview of current diagnostics methods}

Manual muscle testing should be performed in the antigravity position using techniques described by the MRC [4] to allow detection of minimal weakness. According to MRC guidelines, a scale from 0 to 5 is used with 0 denoting no movement because of weakness, 3 representing antigravity, and 5 representing normal strength.

A common feature for all of the above-mentioned scales is that the muscle strength and joint range of motion are evaluated on the grounds of individual subjective perception of an interacting operator. Gradation made using 
TABLE I

Medical Research Council (MRC) scale for muscle strength [4].

\begin{tabular}{c|l}
\hline \hline Grade & Effort \\
\hline 5 & Muscle contracts against full resistance \\
\hline 4 & $\begin{array}{l}\text { Strength reduced, but contraction can still } \\
\text { move joint against resistance }\end{array}$ \\
\hline 3 & $\begin{array}{l}\text { Strength further reduced so that joint can be } \\
\text { moved only against gravity with examiner's re- } \\
\text { sistance completely removed }\end{array}$ \\
\hline 2 & $\begin{array}{l}\text { Muscle can only move if resistance of gravity } \\
\text { is removed. }\end{array}$ \\
\hline 1 & $\begin{array}{l}\text { Only a trace or flicker of movement is seen or } \\
\text { felt, or fasciculations are observed }\end{array}$ \\
\hline 0 & No movement
\end{tabular}

Lovett scale (LT) [5].

TABLE II

\begin{tabular}{l|l}
\hline \hline \multirow{2}{*}{ Terms } & Definitions \\
\hline \multirow{2}{*}{ No evidence of contractility } & Grade: 0 \\
\cline { 2 - 2 } & LT: 0 (zero) \\
\hline \multirow{2}{*}{ Slight contractility, no movement } & Grade: 1 \\
\cline { 2 - 2 } & LT: T (trace) \\
\hline \multirow{2}{*}{ Full range of motion, gravity eliminated } & Grade: 2 \\
\cline { 2 - 2 } & LT: P (poor) \\
\hline \multirow{2}{*}{ Full range of motion with gravity } & Grade: 3 \\
\cline { 2 - 2 } & LT: F (fair) \\
\hline Full range of motion against gravity, & Grade: 4 \\
\cline { 2 - 2 } some resistance & LT: G (good) \\
\hline Full range of motion against gravity, & Grade: 5 \\
\cline { 2 - 2 } full resistance & LT: N (normal)
\end{tabular}

TABLE III

Clinical grading scale employed for functional assessments [6].

\begin{tabular}{c|l}
\hline \hline Grade & Description \\
\hline 0 & Normal \\
\hline 1 & No disability; minor sensory signs or areflexia \\
\hline 2 & $\begin{array}{l}\text { Mild disability; ambulatory for }>200 \mathrm{~m} \text {; mild } \\
\text { weakness in one or more limbs and sensory } \\
\text { impairment }\end{array}$ \\
\hline 3 & $\begin{array}{l}\text { Moderate disability; ambulatory for }>50 \mathrm{~m} \\
\text { without stick; moderate weakness MRC Grade } \\
4 \text { and sensory impairment }\end{array}$ \\
\hline 4 & $\begin{array}{l}\text { Severe disability; able to walk }>10 \text { m with sup- } \\
\text { port of stick; motor weakness MRC Grade 4 and } \\
\text { sensory impairment }\end{array}$ \\
\hline 5 & $\begin{array}{l}\text { Requires support to walk 5 m; marked motor } \\
\text { and sensory signs }\end{array}$ \\
\hline 6 & $\begin{array}{l}\text { Vannot walk 5 m, able to stand unsupported } \\
\text { and able to transfer to wheelchair, able to feed } \\
\text { independently }\end{array}$ \\
\hline 7 & $\begin{array}{l}\text { Bedridden, severe quadriparesis; maximum } \\
\text { strength MRC grade 3 }\end{array}$ \\
\hline 8 & $\begin{array}{l}\text { Respirator or severe quadriparesis; maximum } \\
\text { strength MRC grade 2 }\end{array}$ \\
\hline 9 & Respirator and quadriplegia \\
\hline 10 & Dead
\end{tabular}

such scales is not precise as is based on qualitative expressions such as "weak", "strong", or "normal". Lovett and MRC scale describe test results in terms of numbers, but the meaning of the values is rather symbolical than quantitative. In the literature, some attempts are described to improve MRC for Muscle Strength Scale [7]. Nevertheless, it still describes these movability parameters in an imprecise and unrepeatable way.

Due to continuous development of the evidence base, the medical science is in need of an uncomplicated method of monitoring weakness in an objective, accurate (for example, expressed in precise defined measure units), and repeatable way, specifying the strength and the range of motion.

\section{Methods and measurements}

The clinical problem described above was undertaken at the Faculty of Medical Sciences at the University of Warmia and Mazury (UWM). For this purpose, a device has been invented to measure the range of plantar and dorsal flexion and torque in reaction to the effects induced by calf muscles tendon and the flexors tendons. The device developed at the Department of Mechatronics and IT Education UWM and shown schematically in Fig. 1, consist of three main parts: (1) foot base, (2) force sensor, and (3) crus base.

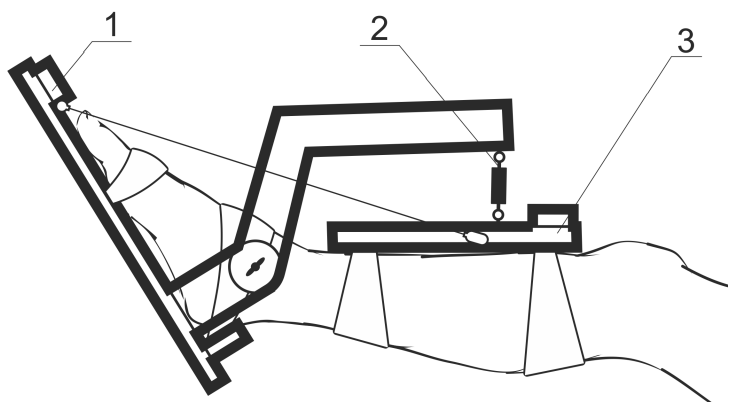

Fig. 1. A schematic diagram of the invented device with indicated main parts.

In accordance with the schedule presented in Fig. 2, the strength and range of motion in ankle joint were measured before and after the surgery.

So far, the medical science lacks a fast and simple method of determining biomechanical characteristics of the muscle system [8]. In the experiment, a modified static characteristics were established. The torque of muscle strength measurements were taken in Subtalar Neutral Position (STN) defined as neither supinated nor pronated [9] what means that the current length of muscle was equal to the resting length $l_{0}$. In the flowchart (Fig. 2), such position is denoted as the survey position. In this case, the passive force component equals zero [8]. The modification concern with interactive measurement of alter strength being the result of the muscle force of patients following after the instructions given by operator. 


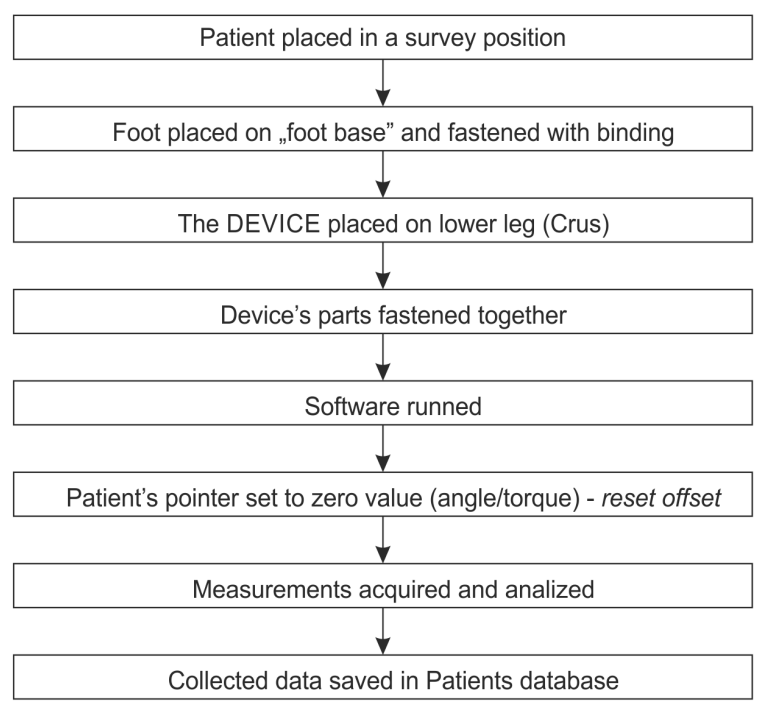

Fig. 2. A flowchart of the measurement procedure.

The instructions were visualized on the screen of a PC computer in graphical form and expressed different values of torque that patients were requested to apply. The values and their time dependencies could be grouped in various scenarios. In the experiment there was an applied scenario with values altering as the sinus function for the frequency of $0.1 \mathrm{~Hz}$. The measured values are presented in units of torque (daNm). All of the patients were volunteers, hospitalized at the Neurosurgery Department at the Hospital of the University of Warmia and Mazury in Olsztyn. The tests were taken prior to surgery and on the first day after the procedure. On the first day after the operation, local swollen occurred and anesthesia could interfere with patient's movement. The duration of measurement was about 25-30 minutes.

\section{Results and discussion}

Results of measurements for selected operator scenario are presented in the Fig. 3. The solid lines illustrates torques, grey - before, black - after the surgery. The dotted lines illustrate the levels of means of extreme values for plantar and dorsiflexion for left and right leg denoted

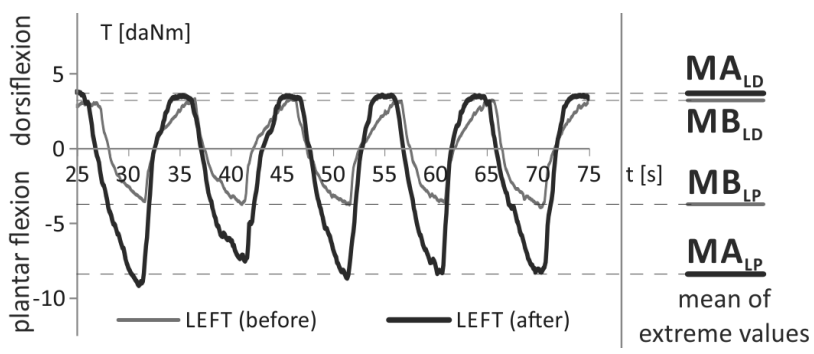

Fig. 3. Torque (before vs. after surgery left paresis leg). as: $\mathrm{MB}_{\mathrm{LD}}$ (mean value before surgery left leg dorsiflexion), $\mathrm{MB}_{\mathrm{LP}}$ (mean value before surgery left leg plantar flexion), $\mathrm{MA}_{\mathrm{LD}}$ (mean value after surgery left leg dorsiflexion), and $\mathrm{MA}_{\mathrm{LP}}$ (mean value before surgery left leg plantar flexion).

Comparison of the results acquired before and after the surgery is presented in Table IV and Table V. The relationship between them given in Table IV is defined as the improvement ratio $\left(I_{r}\right)$

$$
I_{r}=\frac{M A}{M B} \times 100 \%
$$

where $M A$ and $M B$ are mean value after surgery and mean value before surgery for each leg and direction respectively.

TABLE IV

Values obtained and calculated from measurements.

\begin{tabular}{l|l|l|c}
\hline \hline \multirow{2}{*}{ Direction } & \multicolumn{2}{|c|}{ Value } & $I_{r}[\%]$ \\
\hline \multirow{2}{*}{ dorsiflexion } & $\mathrm{MB}_{\mathrm{LD}}$ & $3.30 \mathrm{daNm}$ & \multirow{2}{*}{109.4} \\
\cline { 2 - 3 } & $\mathrm{MA}_{\mathrm{LD}}$ & $3.61 \mathrm{daNm}$ & \\
\hline \multirow{2}{*}{ plantar flexion } & $\mathrm{MB}_{\mathrm{LP}}$ & $3.87 \mathrm{daNm}$ & \multirow{2}{*}{223.8} \\
\cline { 2 - 3 } & $\mathrm{MA}_{\mathrm{LP}}$ & $8.66 \mathrm{daNm}$ &
\end{tabular}

TABLE V

Values of maximal torques and the plantar flexion/ dorsiflexion ratio (RPD), before and after the surgery.

\begin{tabular}{c|c|c|c}
\hline \hline \multirow{2}{*}{ Surgery } & \multicolumn{2}{|c|}{ Value } & \multirow{2}{*}{ RPD } \\
\hline \multirow{2}{*}{ before } & $\mathrm{MB}_{\mathrm{LD}}$ & $3.30 \mathrm{daNm}$ & \multirow{2}{*}{1.17} \\
\cline { 2 - 3 } & $\mathrm{MB}_{\mathrm{LP}}$ & $3.87 \mathrm{daNm}$ & \\
\hline \multirow{2}{*}{ after } & $\mathrm{MA}_{\mathrm{LD}}$ & $3.61 \mathrm{daNm}$ & \multirow{2}{*}{2.40} \\
\cline { 2 - 3 } & $\mathrm{MA}_{\mathrm{LP}}$ & $8.66 \mathrm{daNm}$ & \multirow{2}{*}{}
\end{tabular}

Table $\mathrm{V}$ presents values of mean of maximal torques and RPD between plantar flexion and dorsiflexion defined as

$$
R_{\mathrm{PD}}=\frac{\mathrm{M}_{\mathrm{LP}}}{\mathrm{M}_{\mathrm{LD}}}
$$

before and after the surgery.

The results obtained in "classical" examination expressed in the Lovett scale were: 2 before and 4 after the surgery. The values of maximal torque recorded with the device in the experiment were: $\mathrm{MB}_{\mathrm{LD}}=3.30 \mathrm{daNm}$; $\mathrm{MB}_{\mathrm{LP}}=3.87 \mathrm{daNm} ;$ and $\mathrm{MA}_{\mathrm{LD}}=3.61 \mathrm{daNm}, \mathrm{MA}_{\mathrm{LP}}=$ 8.66 daNm.

\section{Conclusions}

Both examinations show significant improvement of motion abilities; however, the numerical results are free of subjective perception of the person that conducts the examination. In further investigations, additional information should be gathered about the patients to prepare correct factors for the sake of their individual physical features. In the classical method based on the Lovett 
scale, intuition and experience of the examiner have a significant impact on the obtained results. Much more precise metrics in the case of evaluating result of the surgery could be the ratio of improvement equal to the quotient of the muscle strength after and before the surgery. The relevant example is shown in Table IV.

Significant disadvantage of the Lovett scale is the impossibility of expressing the natural difference between torque of dorsiflexion and planar flexion. The reason of this difference is the proportion of dimensions of particular group of muscles responsible for these contrary actions. The relationship between cross section area of the muscles and muscle strength [10] is approximately linear. The relationship between the forces of muscles responsible for plantar flexion and the forces of muscles responsible for dorsiflexion determine the constant parameter which could be taken as a base for quantitative estimation of paresis. This feature seems to be much more independent from such patient's characteristics as age or weight. As can be seen in Table $\mathrm{V}$, ratio of plantar flexion and dorsiflexion after surgery $\left(\mathrm{MA}_{\mathrm{LP}}, \mathrm{MA}_{\mathrm{LD}}\right)$ is 2.40. Such asymmetry provides explicit information that the patient's condition after the surgery is close to typical for the healthy men $[12,13]$.

\section{References}

[1] M.S. Greenberg, Handbook of Neurosurgery - Seventh Edition, Thieme Publishers Series, Greenberg Graphics, 2010

[2] M. Mumenthaler, C. Bassetti, C. Daetwyler, Neurologic Differential Diagnosis, Georg Thieme Verlag, Stuttgart 2005, (in German).
[3] W. Kloc, B.L. Imieliński, M. Majkowicz, J. Kaniszewska, J. Mechlińska-Baczkowska, World Spine 1. First Interdisciplinary World Congress on Spinal Surgery and Related Disciplines, Berlin 2000, Eds.: M. Brock, W. Schwartz, C. Wille, Monduzzi Editore, Bologne 2000, p. 331.

[4] Medical Research Council. Aids to the examination of the peripheral nervous system, Memorandum no. 45, Her Majesty's Stationery Office, London, 1981.

[5] W. Maksymowicz, Principles of neurosurgery, PZWL, Warszawa 1999, (in Polish).

[6] A.F. Hahn, C.F. Bolton, N. Pillay, C. Chalk, T. Benstead, V. Bril, K. Shumak, M.K. Vandervoort, T.E. Feasby, Brain 119, 1055 (1996).

[7] T. Paternostro-Sluga, M. Grim-Stieger, M. Posch, O. Schuhfried, G. Vacariu, C. Mittermaier, C. Bittner, V. Fialka-Moser, J. Rehabil. Med. 40, 665 (2008).

[8] A. Morecki, J. Knapczyk, K. Kędzior, Mechanisms and manipulators theory, WNT, Warszawa 2004.

[9] C. A. Oatis, Physical Therapy 68, 1815 (1988).

[10] D. Tejszerska, E. Świtoński, M. Gzik, Biomechanics of human locomotor, Instytut Technologii Eksploatacji - PIB, Radom 2011.

[11] J. Woodburn, D. E. Turner, P. S. Helliwell, S. Barker, Rheumatology 38, 1260 (1999).

[12] A. Moraux, A. Canal, G. Ollivier, I. Ledoux, V. Doppler, C. Payan, J.-Y. Hogrel, BMC Musculoskeletal Disorders 14, 104 (2013).

[13] S. Poulis, R.W. Soames, Isokinetics Exercise Science 11, 117 (2003). 